\title{
The role of universities in innovation and sustainable development
}

\author{
G. Vidican \\ Engineering Systems and Management Program, \\ Masdar Institute of Science and Technology, UAE
}

\begin{abstract}
The role of universities in innovation and economic development has been widely documented. However, universities' contribution to sustainable development and innovation in renewable energy technologies has not been previously researched. We use case study analysis to explore the knowledge exchange mechanisms between university and industry in fostering innovation in the solar photovoltaic sector and to sustainable development in general, in different locales. We believe that universities play a key role in both technology development and economic growth, and we hypothesize that the way in which these goals are achieved depends on the specifics of the sector, the local economy, and the larger institutional environment.

We find that the role of universities in innovation and sustainable development is most valuable for the private and public sector in five main areas: (a) contributing to fundamental research; (b) combining existing knowledge; (c) education and training (curriculum development); (d) creating space for open exploration of ideas; (e) community involvement. Hence, what matters is not only technology development, but also contributions in terms of assimilation and absorption of these factors by various social groups, such that the result is a change in behaviour or practices.
\end{abstract}

Keywords: universities, innovation, sustainability, renewable energy, solar photovoltaic.

\section{Introduction}

The last decade has been marked by new evidence showing the urgency of climate change problems and calling for action to not only better understand 
their origins, but also to take steps for promoting sustainable development models [1]. These concerns begun to question the mainstream economic growth models, and they highlighted gaps in specialized knowledge, policy and regulatory infrastructure needed to adequately respond to these challenges [2]. Moreover, since climate change and the environment are global problems rather than local or regional, the workings of the society as a whole have been called into scrutiny [3]. To respond to these challenges, innovations are required not only in the technology realm for exploring alternative energy sources, but also in the organizational domain (how firms, governments, and other organizations operate) and in the social behaviour patterns [4].

Historically, higher education institutions have been praised for their contribution to creating new knowledge, advancing the technology frontier, fostering economic development, and being agents of change in the local and regional communities. Given the larger global climate change debate, this paper explores what role universities play in fostering innovation and in promoting sustainable development.

Universities' contribution to innovation and economic development has been widely documented. Earlier studies show that the manner in which universities foster innovation is contingent on the technology that is being developed and on industry characteristics [5]. In addition, public policy and regional growth trajectories influence the contribution that universities make to economic development. However, the way in which universities contribute to sustainable development and innovation in renewable energy technologies has not been previously researched. Given the specific context created by global climate change debates, the systemic nature of environmental problems, and the societal implications of sustainable development goals, we expect that the role played by education and research institutions, such as universities, needs to be reexamined.

We use case study analysis to explore how research universities contribute to the sustainability agenda and to fostering innovation in renewable energy technologies. Our industry case study is the solar photovoltaic sector in Eastern Massachusetts and in the Silicon Valley area. We draw on the rich literature on innovation in different sectors in order to identify differences in the way universities contribute to innovation across sectors. Moreover, we examine the nature of collaborations with the industry and the public sector in promoting and contributing to sustainable regional development. We believe that universities play a key role in both technology development and economic growth, and we hypothesize that the way in which these goals are achieved depends on the specifics of the sector, the local economy, and the larger institutional environment.

Our findings confirm earlier research that universities are critical for innovation and economic development. However, we find that the mechanisms through which universities contribute to innovation in renewable energy and to achieving sustainable development goals, are different. Because of the emerging nature of the industry, most incremental technological innovations are being developed by companies in-house. However, universities are critical in pushing 
the technological frontier and in setting up the agenda for future research, by providing a space where researchers, the private sector, and the government, can come together to explore technology and industry pathways. In addition, universities are instrumental in creating new domains of knowledge that support the development of renewable energy technologies and address larger societal concerns regarding sustainability.

The paper is organized as follows. We begin with a brief discussion on earlier research exploring the role of universities to innovation and economic growth. Section 3 introduces the case studies and the research methods used to collect and analyze the data. In section 4 we discuss the main results in light of existing literature. We highlight the main conclusions and policy recommendations in section 5 .

\section{Universities' contribution to innovation and growth}

Universities have been a subject for research by social scientists and engineers for a long time. The primary focus has been on the specific way in which universities contribute to technological innovation and knowledge diffusion. Fewer studies, however, have examined universities' contribution to economic growth and community development in the regions where they operate. There is wide consensus that universities are sources of new ideas that may eventually transfer to the market, but there is much debate about how these transfers actually occur and what is their economic significance [6]. This section reviews the more recent literature on these two areas.

Research concerned with the role of universities in technological innovation highlight that there are inter-industry differences in the specific way in which universities contribute to innovation [7-9]. As Mowery [5] also mentions, in biotechnology and pharmaceuticals, university research advances affect industrial innovation more significantly and directly than is true of other sectors. In other technological fields, the most commercially significant inventions came from the non-academic research centres. University based research was viewed as instrumental in enhancing fundamental knowledge for manufacturing processes, product innovation, and experimental techniques [5].

Lester and Piore [10] summarize four main areas in which universities contribute to industrial transformation: (a) education and training; (b) adding to the stock of codified knowledge through publications in the technical literatures, patents, software and hardware prototypes; (c) increasing the local capacity for scientific and technological problem-solving; (d) providing space for open-ended conversations about industry development pathways and new technological and market opportunities. By surveying industry managers and researchers (primarily from large manufacturing based companies), Cohen et al. [7] finds that patents and licenses emerging from university research laboratories (or from national research laboratories) were reported to be of little importance compared with publications, conferences, informal interaction with university researchers, and consulting. While, as Mowery [5] argues, more research is required to explore and to validate these findings for smaller firms and those involved in other 
sectors, the results are still illustrative of the relative role of universities in innovation.

However, the role of universities is much broader than generating patents, licenses, and publications, or education and training. As Lester [11] argues, universities should be viewed as "creators, receptors, and interpreters of innovation and ideas, as sources of human capital, and as key components of social infrastructure and social capital." Moreover, in partnerships with other participants in economic and social development, universities have a positive economic role to play [12]. Other researchers also emphasized the need to "innovation society" rather than "innovation system" as the framework of analysis for the role of universities $[6,13,14]$. This would allow us to capture not only the technology production, but also changes in behaviour and practice, as part of the innovation process. In the sustainable development context this contribution bares a large importance.

In a multi industry and country research study, Lester [8] finds that the role played by universities varies depending on the industrial transformation pathways taking place in the region where the universities operate. Lester identifies four main innovation-led growth pathways: (1) creating new industries; (2) industry transplantation; (3) diversification of old industry into related new; and (4) upgrading of mature industry. Universities' contribution to economic growth varies from, for example, forefront science and engineering research to education, bridging between disconnected actors, and offering problem solving for industry through contract research, consulting, and other means.

In a different light, universities contribute to community development and coherence, by promoting their core ethical values of equity, transparency, and equality (reference). Through their interaction with the local government, universities can develop programs that involve the local community in a more effective way than the government or the private sector can, while also maintaining their core competence in education and research [15]. However, more research is required to explore the channels through which these contributions can be enhanced for the benefit of the local and regional communities. For larger and more system concerns such as sustainable development, which this paper addresses, we argue that these contributions tend to be more important.

\section{Case study and methods}

To capture the role of universities in innovation within the sustainability domain, we chose to focus on the nature of university involvement in the renewable energy sector. The renewable energy sector is very diverse, depending on the different energy sources (such a biofuels, geothermal, wind, solar), and also on the specific technology used to harness a renewable energy source. Hence, in order to narrow down our analysis even further, we focused on the solar photovoltaic technologies, as one lens through which to explore the role of universities in the renewable energy domain and sustainability. 
For comparative purposes we chose two locales, Eastern Massachusetts and Northern California, with well established academic centres and entrepreneurial environments (i.e. Route 128 and Silicon Valley, respectively). These two locations also have the largest concentration of companies involved in the solar photovoltaic industry spanning across the entire value chain. There are about 65 companies in Massachusetts and more than 200 companies in California, most of these being located in the Silicon Valley.

The primary method of data collection was in-depth qualitative semistructured interviews with university researchers, solar photovoltaic companies, and public policy officials. We developed separate interview protocols for the different players we interviewed, focusing the discussion around the nature of collaborations between universities, private and public sector; the role of universities in developing a sustainability research agenda and in innovation for renewable technologies; the history and nature of engagement of different organizations with sustainability related issues. We conducted 21 interviews in Massachusetts and 46 in California between February-November 2008. The interviews were recorded, transcribed, and coded using specialized statistical software for qualitative research.

\section{Discussion}

The role of universities in innovation and sustainable development transpired as important in several areas, which I will discuss in greater detail below: (1) contributing to fundamental research; (2) combining existing knowledge; (3) education and training (curriculum development); (4) creating space for open exploration of ideas; and (5) community involvement.

\subsection{Contribution to fundamental research}

Universities are commonly known for their contribution to the advancement of science in different domains. When it comes to the renewable energy domain, this role becomes even more important. With strong pressures for developing solar PV technologies with high efficiency and low cost, universities are seen as the most suitable to engage in such research. Due to the high risk of failure and longer timeframe for obtaining the required results, such areas are being pursued by university researchers. In the case of solar PV, this research consists of exploring new materials and discovering new technologies.

Most applied research is being done by companies in-house. Discussions with researchers at universities and companies revealed several reasons that explain this trend for the case of solar PV sector. First, the solar PV market grew significantly in the past decade, both in terms of installed capacity, as well as in terms of the number of companies coming into the market. As a result, the level of competition has intensified as well. Second, companies and universities are inherently different regarding their commitment to transparency and free exchange of information. While universities are committed to exchanging ideas and knowledge, because of competitive pressures, firms are more proprietary with their research ideas and programs they are engaged in. Hence, most applied 
research is being conducted by companies in-house, similar to what has been observed in other sectors as well.

However, in the past decades, because of limited research funds from the federal government, there is a trend in universities to be more involved in applied research (with funding from the private sector), creating tension and generating debate regarding their role and core mission. Our research results suggest that the main concern is not the source of the research funds, but rather on what type of research the funds are spent. For instance, at Stanford, most research on solar PV technologies (and renewables in general) was funded by the private sector. A lot of the projects had, however, a strong fundamental research component, and funding was coming from large oil companies. Nevertheless, more research is needed to unearth subtleties related to how the source of funding affects the scope of the research project.

\subsection{Combining existing knowledge}

Sustainability is a new domain of knowledge. Even if discussions of sustainability principles have been in the academic and policy domain ever since the 1960s, a coherent body of theory, policies, and research on these issues has only recently become part of the agenda. Within this effort, universities are seen as important players in combining existing knowledge into new domains of knowledge or of analysis. However, this task (or contribution) does not come easily to universities, where disciplines and departments are separated by clearly set boundaries. Nevertheless, crossing disciplinary boundaries is a defining characteristic of sustainability and renewable energy technologies.

Our research revealed that to be able to cross-disciplinary boundaries, oftentimes universities need brokers to create opportunities for collaborations and exchange of knowledge with the purpose of creating a new product, process, policy, or theoretical interpretation. Two examples at Stanford reflect this argument. First, the Stanford Photonics Center was created to leverage crossdisciplinary knowledge and to facilitate relationships with the private sector. To do this, a former entrepreneur was brought at the university to identify potentially interesting research, ideas, and to link researchers across departments to collaborate on joined projects. This has been a unique effort and it resulted in new research areas with applications for the solar energy sector.

Another example, still from the Stanford campus, is the Global Climate Change and Energy Project (GCCEP) created with funding from the private sector (three large oil companies) with the purpose of funding interdisciplinary cutting edge research on climate change and alternative energy technologies. The end result of the call for proposals was that researchers in different departments at Stanford and around the world begun to think how they could collaborate and leverage their knowledge into different potential applications. It was because of GCCEP that research on solar energy technologies emerged at Stanford more recently.

These forms of knowledge exploration would not have been possible outside the university campus. However, even at universities, special mandates (or brokers) need to be created to cross the disciplinary boundaries that commonly 
define universities. Nevertheless, enough of these programs will make these processes much easier to achieve, becoming the norm rather than the exception.

\subsection{Education and training}

Universities' core mission is to generate, improve, and disseminate knowledge through education and training. When we consider sustainability and renewable energy technologies, education is critical. Nevertheless, few universities incorporate in their curriculum sustainability elements and specialized courses in renewable energy technologies. Only recently have universities, such as MIT, Stanford, Berkeley, integrated related courses in their curriculum. Most companies, however, suggested that given the fast growth of the solar PV industry, and renewables in general, universities should play a much more active role in preparing the labour force (at different levels) for the new market requirements.

Interviews with different players indicated that there is a lack of skilled labour force at different levels: high-skilled professionals and researchers specialized in cutting-edge solar technologies, as well as skilled labour for system integration. Such concerns have been raised even within universities themselves, primarily by students, leading to major energy related campus initiatives to support this process. Hence, universities and other educational institutions should engage more actively in designing new curriculum to reflect more recent demands from the labour market.

\subsection{Creating space for open exploration of ideas}

More recent studies emphasize that aside from the classic methods for knowledge transfer (i.e. licensing, patents, publications), companies value the opportunity that universities offer for exploratory communication and relationships $[10,11,16]$.

Creating a space for open explorations of ideas with different stakeholders is even more important than in other sectors, such as bio-tech, since the outcomes are much more widespread on the society and on the local economy. Sustainability also requires a rethinking of the current state of affairs in local business organization and the role played by different institutions. Local utilities are also increasingly seeking universities to offer a platform for communication and exploration of different models of operation. Companies often come to universities without a pre-determined question. Rather, they seek and value conversations on future development of the technology and of the industry. Such open-ended conversations can take the form of regular technical meetings, seminars and workshops with different stakeholders, academic or industry conferences.

\subsection{Community involvement}

The role of universities in community involvement has also been identified as important for developing and promoting sustainability principles. It is important 
for universities to involve both the campus community as well as the local community in changing practices, and thinking about policies for implementation. MIT's initiatives for greening the campus have been very successful in engaging the students and faculty in hands-on projects and education aimed at increasing awareness and changing behavioural patterns. Similarly, the engagement of MIT in local environmental initiatives has been important in stimulating grass-roots initiatives in the local communities.

\section{Conclusion}

This paper highlighted five main areas where universities are seem as important contributors to innovation in solar photovoltaic technologies, and in sustainable development more broadly: contributing to fundamental research; combining existing knowledge; education and training; creating space for open exploration of ideas; community involvement. These findings, from interviews with researchers at universities, solar PV companies, and policy-makers in the public sector, suggest that universities should take a more active role beyond their core mission in education, training, and knowledge production. The systemic, societal character of sustainability and energy challenge, calls for universities to leverage their capabilities at a much larger level.

Hence, there is a need for universities to expand their defined role in the society. What matters is not only for universities to create new technologies, but also to contribute in terms of assimilation and absorption of these factors by various social groups, such as that the result is observable change in behaviour or practices, as well as technology adoption. Along these lines, innovation should be viewed in broader terms to take into account not only the technology aspects, but also the social aspects that underpin the innovation process, which are critical for the sustainability domain of knowledge.

\section{References}

[1] Stern, N., Stern Review: The Economics of Climate Change, New Economics Foundation, 2006.

[2] Flavin, C., Preface to the State of the World: Innovations for a Sustainable Economy. 2008 State of the World: Innovations for a Sustainable Economy. W. W. Institute, W.W. Norton \& Company: Washington D.C., pp. 1-19, 2008.

[3] Calder, J.S., Mobilizing Human Energy. 2008 State of the World: Innovations for a Sustainable Economy. W. W. Institute. Washington D.C., W.W. Norton \& Company: Washington D.C., pp. 166-179, 2008.

[4] Talberth, J., A New Bottom Line for Progress. 2008 State of the World: Innovations for a Sustainable Economy. W. W. Institute, W.W. Norton \& Company: Washington D.C., pp. 18-31, 2008.

[5] Mowery, D.C., The Bayh-Dole Act and High-Technology Entrepreneurship in U.S. Universities: Chicken, Egg, or Something Else? Paper Presented at 
Entrepreneurship Education and Technology Transfer, University of Arizona, January 21-22, 2005.

[6] Hawkins, R.W., Langford, C.H. \& Sidhu, K.S., University Research in an Innovation Society. Science, Technology and Innovation Indicators in a Changing World: Responding to Public Needs, OECD, 2007.

[7] Cohen, W. M., Goto A., Nagata, A., Nelson, R.R. \& Walsh, J.P., R\&D Spillovers, Patents, and the Incentives to Innovate in Japan and the United States. Research Policy 31(8-9), pp. 1349-1367, 2002.

[8] Levin, R., Klevorick, A., Nelson, R. \& Winter, S., Appropriating the Returns from Industrial R\&D. Brookings Papers on Microeconomics, pp. 783-831, 1987.

[9] Mansfield, E., Academic Research and Industrial Innovation: An Update of Empirical Findings. Research Policy 26(7-8), pp. 773-776, 1991.

[10] Lester, R.K. \& Piore, M., Innovation: The Missing Dimension, MIT Press: Cambridge, 2004.

[11] Lester, R.K., Universities, Innovation, and the Competitiveness of Local Economies. A Summary Report from the Local Innovation Systems Project - Phase I. MIT Industrial Performance Center Working Paper 05-010: Cambridge, 2005.

[12] Gray, H., Preface. Universities and the Creation of Wealth, ed. H. Gray, The Society for Research into Higher Education \& Open University Press: Buckingham, pp. 1-10, 1999.

[13] Cowan, R., Cowan W. \& Swann, P., Waves in Consumption with Interdependence Among Consumers. Canadian Journal of Economics 37(1), pp: 149-77, 2004.

[14] McMeekin, A., Green, K., Tomlinson, M. \& Walsh, V., Innovation by Demand: An Interdisciplinary Approach to the Study of Demand and Its Role in Innovation, UK, Edward Elgar: Cheltenham U.K., 2002.

[15] Rappaport, A. \& Hammond Creighton, S., Degrees That Matter: Climate Change and the University. MIT Press: Cambridge, 2007.

[16] Cosh, A., Hughes, A. \& Lester, R.K., University-Industry Linkages and U.K. Science and Innovation Policy. Working Paper No. 326, Centre for Business Research, University of Cambridge: Cambridge U.K., 2006. 